\title{
A REVIEW OF 3D GIS FOR USE IN CREATING VIRTUAL HISTORIC DUBLIN
}

\author{
Alain Chenaux, ${ }^{1}$, M Murphy ${ }^{2}, \mathrm{~S} \mathrm{Pavia}^{2}, \mathrm{~S} \mathrm{Fai}^{3}, \mathrm{~T}$ Molnar $^{3}$, J Cahill ${ }^{4}$, S Lenihan ${ }^{4}$, A Corns ${ }^{5}$, \\ ${ }^{1}$ School of Surveying and Construction Management, Dublin Institute of Technology, Alain.Chenaux@dit.ie \\ 2 Trinity College Dublin, maurice.m.murphy@gmail.com, pavias@tcd.ie \\ ${ }^{3}$ Carleton University, ThomasJMolnar@cmail.carleton.ca, Stephen Fai cims@bell.net \\ ${ }^{4}$ Office of Public Works, John.Cahill@OPW.ie, shane.lenihan@opw.ie \\ ${ }^{5}$ Discovery Programme, anthony@discoveryprogramme.ie
}

\author{
Commission II \\ KEY WORDS: Historic City Modelling, GIS, HBIM, Laser Scanning, 3D Modelling, PostGreSQL/PostGIS
}

\begin{abstract}
:
This paper illustrates how BIM integration with GIS is approached as part of the workflow in creating Virtual Historic Dublin. A design for a WEB based interactive 3D model of historic buildings and centres in Dublin City (Virtual Historic Dublin City) paralleling smart city initiates is now under construction and led by the National Monuments at the Office of Public Works in Ireland. The aim is to facilitate the conservation and maintenance of historic infrastructure and fabric and the dissemination of knowledge for education and cultural tourism using an extensive Historic Building Information Model. Remote sensing data is now processed with greater ease to create 3D intelligent models in Historic BIM. While the use of remote sensing, HBIM and game engine platforms are the main applications used at present, 3D GIS has potential to form part of the workflow for developing the Virtual Historic City. 2D GIS is now being replaced by 3D spatial data allowing more complex analysis to be carried out, 3D GIS can define and depict buildings, urban rural centres in relation to their geometry topological, semantic and visualisation properties. The addition of semantic attributes allows complex analysis and 3D spatial queries for modelling city and urban elements. This analysis includes fabric and structural elements of buildings, relief, vegetation, transportation, water bodies, city furniture and land use.
\end{abstract}

\section{INTRODUCTION}

As an attempt to digitally assemble connected tangible and intangible cultural heritage assets the Virtual Historic Centre is proposed as a dynamic digital repository and portal. By adding information and knowledge as semantic attributes to remotely sensed survey data, this then moves digital objects from static representations to dynamic, interactive and 'smart' models. Historic Building Information Modelling (HBIM) and Heritage GIS can encompass the automated data capture then used for information and knowledge extraction in addition to visualisation for cultural heritage centres.

\section{RELATED WORKS}

\subsection{Geographic Information Systems (GIS)}

A Geographic Information System (GIS) is used for storing, visualizing and analyzing geographic data. Spatial features are stored as geometry and referenced with map projections and coordinates. Attributes stored in tables are then associated with spatial features to allow for analysis of data. 2D GIS is now being replaced by 3D spatial data allowing more complex analysis to be carried out. 3D GIS can define and depict buildings, urban rural centres in relation to their geometry topological, semantic and visualisation properties. The addition of semantic attributes allows complex analysis and 3D spatial queries for modelling city and urban elements. This analysis includes fabric and structural elements of buildings, relief, vegetation, transportation, water bodies, city furniture and land use.
As stated previously, Geographical information systems (GIS) have progressed from $2 \mathrm{D}$ or $2.5 \mathrm{D}$ to $3 \mathrm{D}$, CityEngine now part of ArcGIS platform encompasses procedural modelling technique based on shape grammars which are combined using architectural rules to create shape arrangements for building types, facilitating automation for 3D City modelling. Shape grammars, introduced the concept that buildings are based on different architectural styles and can be divided and represented by sets of basic shapes which are a limited arrangement of straight lines in three-dimensional Euclidian space. These shapes are governed by replacement rules whereby a shape can be changed or replaced by transformations to create more complex and additional shapes. Parametric variables allow shape deformation and location change within 3D environments (Stiny and Gips, 1972; Muller et al, 2006; Parrish et al 2001).

\subsection{Historic Building Information Modelling (HBIM)}

By adding information and knowledge as semantic attributes to remotely sensed survey data, this then moves digital objects from static representations to dynamic, interactive and 'smart' models. Historic Building Information Modelling (HBIM) similar to Heritage GIS encompass the automated data capture of existing structures and sites followed by mapping of parametric and information rich objects onto a geometric framework developed from survey data. The resultant Historic BIM can then be used for information and knowledge extraction in addition to visualisation. As a multi-disciplinary and evolving system, researchers from computing, architecture, archaeology, engineering and other heritage areas are improving the process for efficiency and for creating more open systems (Murphy et al, 2013; Hichri et al, 2014; DeLuca et al, 2012) 


\subsection{BIM and GIS}

City Information Modelling (CIM) is an integrated multiplatform combining Geographical Information Systems (GIS) and Building Information Modelling combining geospatial data and building attributes and behaviour. Unfortunately the transformation from Industry Foundation Classes (IFC) to BIM is still not solved. The CIM open source BIMserver only exports IFC to CityGML LOD4, (De Laat, R. and Van Berlo, 2011). Many other researchers have used a workflow which converts 3D models to Sketchup which then is imported into City GML or ArcGIS.

\subsubsection{City GML}

CityGML is an international standard data format for representing 3D cities and data based on Extensible Markup Language (XML) format which is an application of the Geographic Markup Language 3 (GML3). CityGML describes objects in relation to their geometrical, topological, semantical and appearance properties. With the addition of topology and semantic information complex analysis and 3D spatial queries can be carried out in a GIS environment (Del Gado et al, 2010; Goetz, 2013).

\subsubsection{Conversion of Historic BIM to GIS}

Dore and Murphy's (2012) work involved converting the HBIM model for Henrietta Street into CityGML for further GIS analysis. Industry Foundation Classes which is the standard for interoperability in Building Information Modelling does not extend to GIS platforms. Therefore in this work it was necessary to export the HBIM model from BIM platform ArchiCAD to Google SketchUp and converted with the CityGML plug-in for SketchUp. SketchUp can maintain geometry and semantic classes (Fig. 3). Further attributes were then added to the $\mathrm{xml}$ file. These attributes included function, class, year of construction, description and address for buildings. The addition of these attributes allows the model to be used for heritage applications and is an interoperable format that enables sharing of data and can be imported into various GIS packages such as ArcGIS.

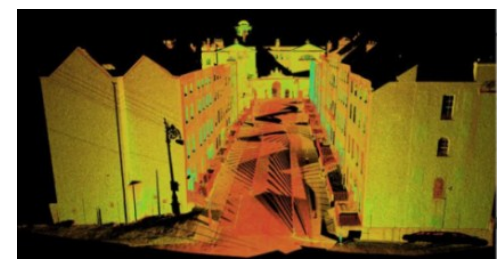

Figure 1: Laser Scan Survey of Henrietta Street

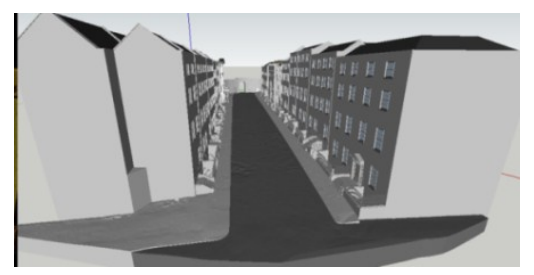

Figure 2: HBIM of Henrietta Street Dublin (modelled from scan in figure 1 and exported to Sketchup)

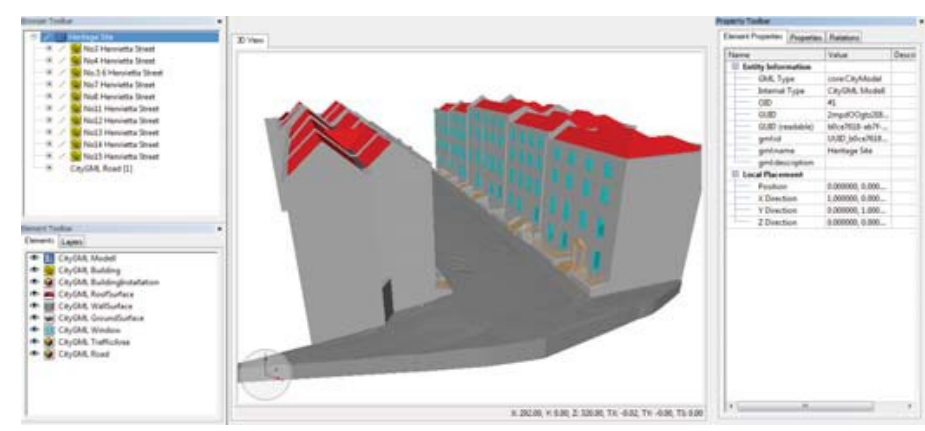

Figure 3: CityGML Model Showing Semantic Classes (Dore and Murphy 2012)

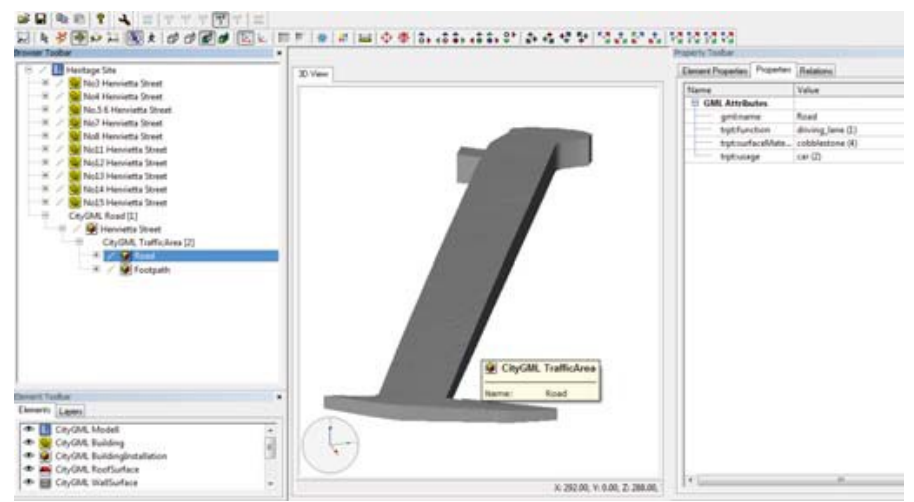

Figure 4: Road Feature Class Showing Associated Attributes (Dore and Murphy 2012)

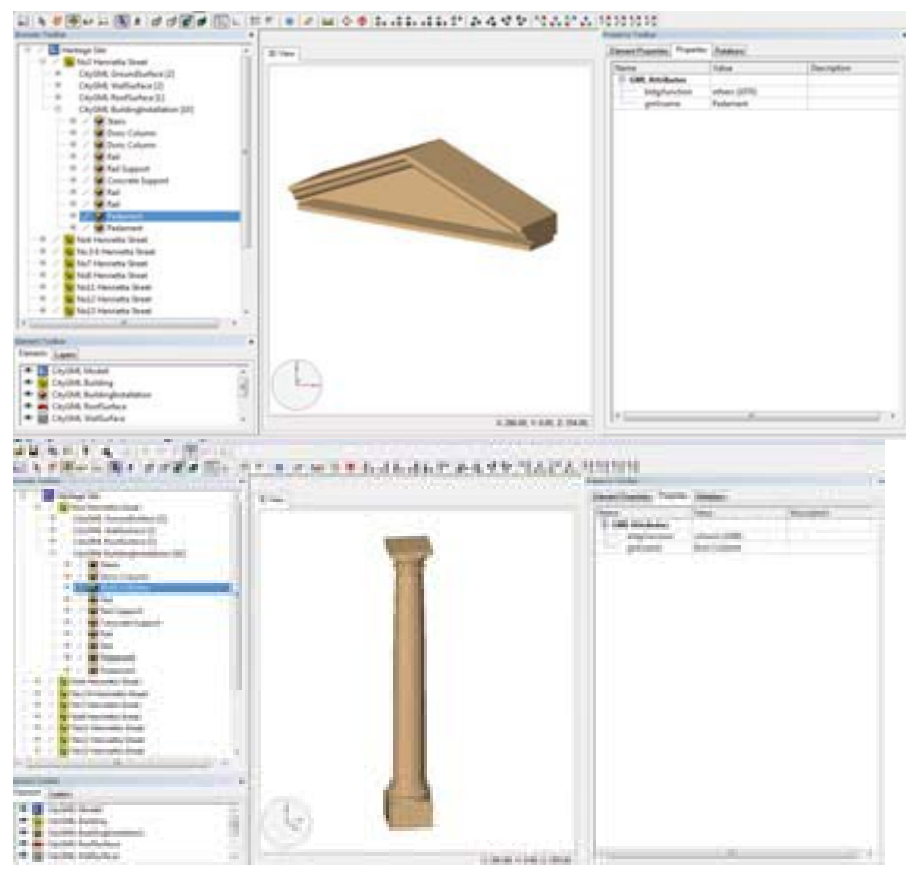

Figure 5: CityGML Objects (Dore and Murphy 2012) 


\section{DEVELOPED METHODOLOGY}

\subsection{HBIM to ArcGIS}

In order to continue and build on the work of Dore and Murphy (2102) the same HBIM data and model were imported into ArcGIS which is a commercial geographic information system with ability to manage and visualise $3 \mathrm{D}$ city models while City GML is an open source software platform. To convert the model into a readable format in ArcGIS 10.6, a script file was written in python using arcpy, a python package for accessing various functions to perform spatial data management, data conversion and spatial analysis (Pimpler, 2015). The script was first run in the python interactive window available in ArcGIS (Figure 6) and the original SketchUp file was imported as a 3D layer into an existing geodatabase.

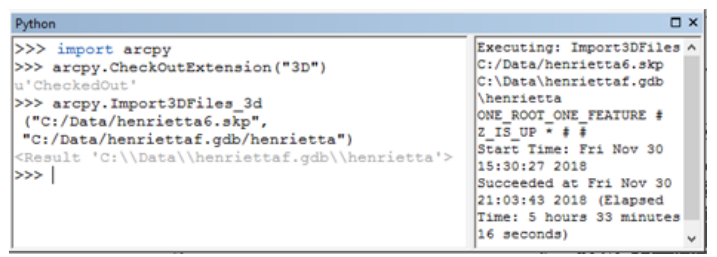

Figure 6 : python script to import SketchUp file into ArcGIS

This 3D layer was then added into ArcScene, a 3D Viewer in ArcGIS which allows displaying, navigating and interacting with 3D spatial data (Figure 7).

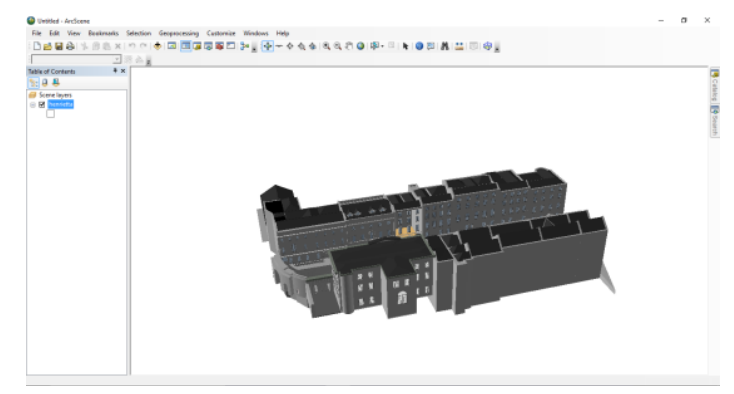

Figure 7: Original SketchUp model displayed in ArcScene

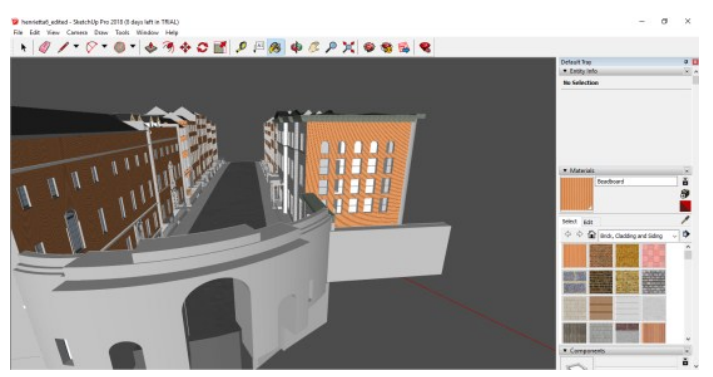

Figure 8: SketchUp model with materials

Materials (i.e. paints which have texture and colour) were added to various types of faces such as walls and roofs in SketchUp
(Figure 8) and the modified model was exported into ArcScene using the same steps as described above (Figure 8 and 9).

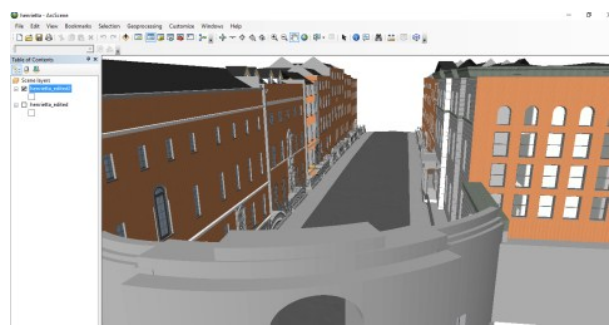

Figure 9: SketchUp model with materials displayed in ArcScene

Point cloud and laser scan survey data can be used with GIS platforms but mainly as a visualisation tool only. It is necessary though to model outside of GIS platform in BIM or 3D CAD tools in order to create textured and symmetrically defined 3D buildings/objects (identified architectural and structural components) and import the models into GIS (Figure 10).

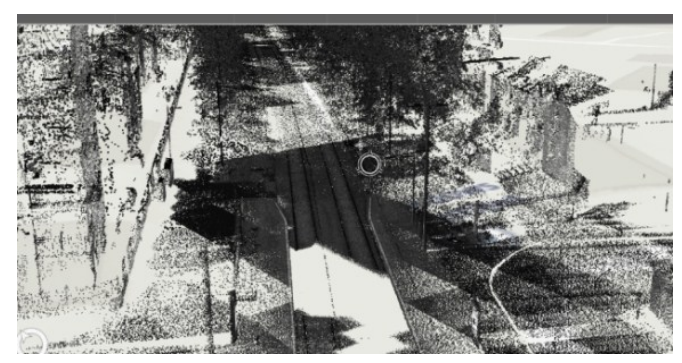

Figure 10: Point Cloud Visualised in GIS (3D Laser Mapping 2018)

\subsection{HBIM to PostGreSQL/PostGIS}

Oracle and Postgre SQL spatial databases are used for managing large datasets. The storage of spatial data in addition to GIS Spatial data sets are primarily defined as those which are directly or indirectly referenced to a location on the surface of the earth and non-spatial data (text, image etc.). Spatial data bases now include vector data which include three geometric primitive types and geometries; 2-D Point and Point Cluster, 2D Line Strings, 2-D N-Point Polygons. PostgreSQL is an open source, object-relational database management system which can be extended to handle 2D and 3D spatial data using an extension called PostGIS (Obe and Hsu, 2011). However, in order to import SketchUp models into PostGIS, a CityGML file must be created from the SketchUp model and a software called 3DCityDB is required to transfer CityGML into PostgreSQL/PostGIS.

3DCityDB is a free Open Source software suite consisting of a database schema allowing the import, manage, analyse, visualise, and export of virtual $3 \mathrm{D}$ city models according to the CityGML standard (Yao et al, 2018). 3DCityDB allows the CityGML data model to be mapped onto the relational schema of spatially-enabled database management system (DBMS) such as Oracle Spatial (since version 10g) and PostgreSQL/PostGIS 
(since, respectively, versions 8.4 and 2.0). It supports very large amount of geometries and texture images and it works in tandem with database management system (DBMS). The 3DCityDB suite also includes a specific WebGL-based 3D web client for interactive visualisation of 3D models (Kunde, 2014). A new spatial database was created in PostgreSQL 9.4/PostGIS 2.2. CityGML data was imported after setting up all the necessary connections between PostgreSQL and 3DCityDatabase. The SFCGAL extension, which augments the 3D spatial analysis for operations such as extrusion or volume calculation (Giovanella et al, 2018; Ryoo et al, 2017), was also added to the database.

When imported into PostGreSQL, CityGML data is organised into a large set of tables and relationships between these tables. Queries can then be computed in SQL to select and extract data over one or several tables. For example, as a building may have several addresses and an address may match more than one building, a weak entity table address to the building needs to also be accessed to find out which flat roof buildings are located on a specific street (Figure 10).

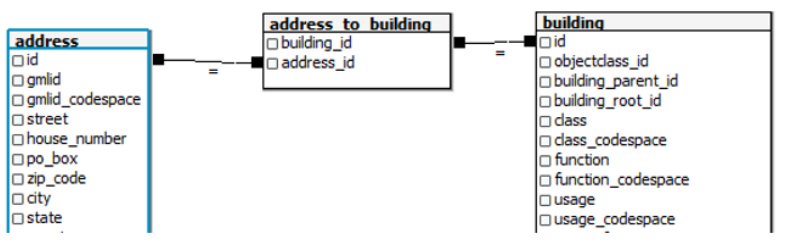

Figure 11: Sample query and related tables and relationships in

$$
\text { PostgreSQL }
$$

Similarly, spatial functions in 2D and 3D can also be accessed when computing queries in SQL. PostGIS uses the ST_ suffix to describe those functions, which include:

- $\quad$ Spatial predicates: which define the spatial relationship between objects, such as ST Intersects, St_Contains, ST_3DIntersects, ST_3DDWithin, etc.

- $\quad$ Spatial methods which compute new geometries from existing ones, for example ST_Buffer, ST_3DBuffer, ST_3DEnvelope, etc.

- Measurement functions such as ST_3DArea or ST_Area (Figure 11)

\begin{tabular}{|l|}
\hline SQL Editor Graphical Query Builder \\
Previous queries \\
\hline SELECT COUNT (DISTINCT c.id) \\
AS "Number of Larger Building Wall Surfaces" \\
FROM \\
citydb.cityobject c, \\
citydb.objectclass $\circ$, \\
citydb.surface_geometry s \\
WHERE c.objectclass_id $=0$. id AND \\
s.cityobject_id $=$ c.id AND \\
o.classname = 'BuildingWallSurface' AND \\
ST_Area (s.geometry) >0.1; \\
\hline
\end{tabular}

Figure 12: Example of spatial query in PostgreSQL

\section{CONCLUSIONS}

\subsection{Initial Findings}

Currently, with the exception of CityEngine, full 3D models, such as those created for city modelling, are first built-up in a CAD environment, have to be spatially referenced and then imported into a GIS package. This results in various issues, such as data inconsistency and data interoperability between CAD and GIS (Jedlička, 2015), including versioning issues; for example, the model in Sketchup 2018 had to be converted into an older version 6 before being imported into ArcGIS 10.6.

The large number of tables and relationships to traverse when performing queries on imported CityGML models into a relational database like PostgreSQL significantly increase the amount of processing time, particularly when larger datasets are imported. Interestingly, the last decade has seen the emergence of databases referred as NoSQL (Not Only SQL) which do not rely on the traditional relational data model (or object-relational model).

One category of NoSQL databases, which include MongoDB and CouchBase, stores data as a collection of documents in XML or JSON format, which would logically be well-suited for storing CityGML files. Even though these database management systems have a limited number of spatial functions compared to PostGIS, MongoDB, for example, performs queries faster by a factor of typically 10 to 25 times than relational databases, particularly as the data size increases (Agarwal \& Rajan, 2017). Mao et al (2014) has proposed a framework using such databases in conjunction with cloud computation to handle CityGML files.

\subsection{Future Work}

The older data sets used in this paper were chosen for consistency and to follow on from the work of Dore and Murphy (2012). The initial findings indicate that GIS and PostGreSQL/PostGIS should form part of the workflow which will be incorporated into the workflow with Remote Sensing, HBIM and Game Engine Platforms for Virtual Historic Dublin.

\subsubsection{Existing Data - Aerial Laser Survey of Dublin City}

The 2015 Aerial Laser and Photogrammetry Survey of Dublin City Collection Record will be used to develop the Virtual Historic City of Dublin, developed from existing data sets of historic 2D mapping and in particular aerial and terrestrial laser and image based surveys. The Lidar and 3D mapping surveys were carried by the School of Engineering UCD in 2008 and 2015 funded by Science Foundation of Ireland and European Research Council. The survey data includes most of Dublin City's medieval and classical historic areas. The high density, aerial remote sensing data for a $2 \mathrm{~km}^{2}$ area of Dublin, Ireland obtained at an average flying altitude of $300 \mathrm{~m}$. The data include aerial laser scanning (ALS) from 41 flight paths in the form of a 3D point-cloud (LAZ) and 3D full waveform ALS (LAS and Pulsewave). Imagery data includes ortho-rectified $2 \mathrm{D}$ rasters (RGBi) and oblique images. The ALS data consist of over 1.4 billion points. The ALS and imagery data are structured both by flight paths and by $500 \times 500 \mathrm{~m}$ rectangular tiles (Laefer, D, F, et al 2018). 


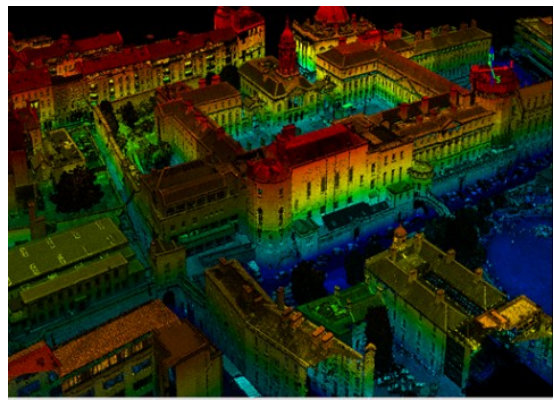

Figure 13: Sample of Aerial Laser and Photogrammetry Survey of Dublin Historic City

4.2.2 Processing the Lidar Data Sets

This point cloud data is at present segmented manually and converted to meshes for importation into HBIM, Game Engine and GIS platforms. Automatic segmentation and meshing will be considered as proposed by Ozdemir and Remondino (2018). Figure 14 illustrates a series of steps which follow illustrate some of the workflows involved for processing Lidar Data Sets as part of Virtual Historic Dublin.

STEP 1 Point cloud merged, cropped, and re-coloured
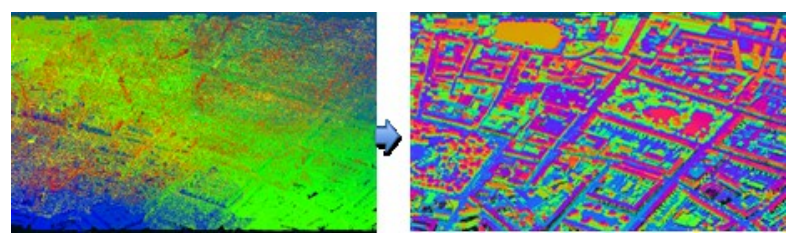

STEP 2 Convert to E57 format files for use in HBIM

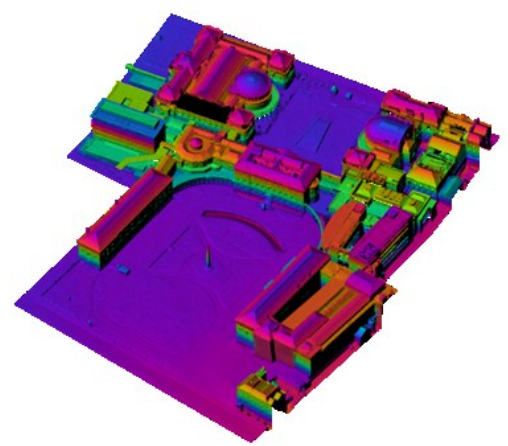

STEP 3 Geo-Magic Wrap and transformed into a mesh, cleaning to remove noise and fill holes in the data

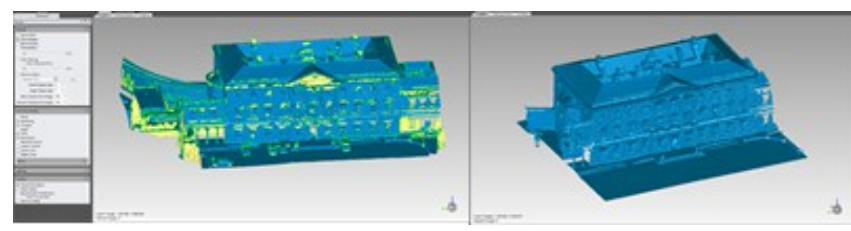

Figure 14: Initial Workflows Involved For Processing Lidar Data Sets.

\subsubsection{Creating Semantically Enriched Objects}

Segmented meshed 3D objects are limited in terms of attaching semantically enriched 3D buildings/objects which can then separate and recognise architectural and structural components and improve LODs. In addition to meshed objects, 3D models which support structural and architectural analysis, must be created separately as 3D CAD objects and then mapped onto the point clouds surveys. The design for creating these objects are based on architectural rules informing shape grammars which are transformed from primitive to complex shapes based on operations such as add/subtract, rotate, deform, extrude etc. The shapes are then arranged to fit the form of historic structures or sites (Murphy et al 2013).

\section{REFERENCES}

3D Laser Mapping, https://www.3dlasermapping.com/blogpost/using-point-clouds-with-gis-part-2/ (Last accessed December 2018)

Agarwal, S., \& Rajan, K. S., 2017. Analyzing the performance of NoSQL vs. SQL databases for Spatial and Aggregate queries. In Free and Open Source Software for Geospatial (FOSS4G) Conference Proceedings (Vol. 17, No. 1, p. 4).

Agosto, E., Ardissone, P., and Rinaudo F., 2007. GIS and WebGIS, Commercial and Open Source Platforms: General Rules for Cultural Heritage Documentation. International Archives of the Photogrammetry, Remote Sensing and Spatial Information Sciences 36: 625-630.

Becker, S., 2012. "Integrated management of heterogeneous geodata with a hybrid 3D geoinformation system". ISPRS Annals of Photogrammetry, Remote Sensing and Spatial Information Sciences. I-2, pp. 87-92. http://dx.doi.org/10.5194/isprsannals-I-2-87-2012

Berlo, L.V. \& Laat, R.D. 2010. 'Integration of BIM and GIS: The Development of the CityGML GeobBIM Extension', paper presented to 5th International 3D GeoInfo Conference, November 3-4, 2010,, Berlin, Germany, Berlin, Germany.

De Luca, L., 2011. 'Methods, formalisms and tools for the semantic based surveying and representation of architectural heritage', Applied Geomatics 6(1866).

Delgado, F., Martínez, R., Hurtado, A. \& Finat, J., 2010. 'Extending functionalities of Management Systems to CityGML', in eWork and eBusiness in Architecture, Engineering and Construction, CRC Press, pp. 409-15.

Dore, C., Murphy, M., 2012. Integration of Historic Building Information Modeling and 3D GIS for Recording and Managing Cultural Heritage Sites, 18th International Conference on Virtual Systems and Multimedia: "Virtual Systems in the Information Society", 2-5 September, 2012, Milan, Italy, pp. 369-376. 
Giovanella, A., Bradley, P. E., \& Wursthorn, S., 2018. Detection and evaluation of topological consistency in CityGML datasets. ISPRS Annals of Photogrammetry, Remote Sensing \& Spatial Information Sciences, 4(4).

Goetz, M., 2013. Towards generating highly detailed 3D CityGML models from OpenStreetMap. Int. J. Geogr. Inf. Sci. $27,845-865$.

Gröger, G. and Plümer, L., 2012. CityGML Interoperable semantic 3D city models. ISPRS Journal of Photogrammetry and Remote Sensing, 71, pp.12-33.

Hichri N., Stefani C., Veron P., Hamon G., De Luca L. 2014. Review of the as built BIM approaches. Journal of Applied Geomatics. Springer Berlin / Heidelberg.

Jedlička, K., 2018. A Comprehensive Overview of a Core Of 3D GIS. Proceedings, 7th International Conference on Cartography and GIS, 18-23 June 2018, Sozopol, Bulgaria

Kunde, F., 2014. CityGML in PostGIS: Portierung, Anwendung und Performanz-Analyse am Beispiel der 3DCityDB Berlin. Unpublished master thesis. Institut für Geographie, Universtät Potsdam, In German only. http://opus. kobv. de/ubp/volltexte/2013/6365. Accessed, 12.

Laefer, D. F., Abuwarda, S., Vu Vo, A., Truong-Hong, L. and Gharibi H., 2015. Aerial Laser and Photogrammetry Survey of Dublin City Collection RecordNew York University. Center for Urban Science and Progress, doi:10.17609/N8MQ0N, https://geo.nyu.edu/?f\%5Bdct_isPartOf_sm $\% 5 \mathrm{D} \% 5 \mathrm{~B} \% 5 \mathrm{D}=201$ 5+Dublin+LiDAR, (Last Accessed December 2018)

Mao, B., Harrie, L., Cao, J., Wu, Z., \& Shen, J., 2014. NoSQL based 3D city model management system. The International Archives of Photogrammetry, Remote Sensing and Spatial Information Sciences, 40(4), 169.

Mccool, J.P., 2014. PRAGIS: a test case for a web-based archaeological GIS. Journal of Archaeological Science. Volumen 41, pp. 133-139.

Mueller, P. Wonka, P, Haegler, S, Ulmer A, and Gool, V, 2006, "Procedural modeling of buildings," ACM Transactions on Graphics, vol. 23, no. 3, pp. $614-623$, July

Murphy, M, McGovern, E \& Pavia, S 2013, 'Historic Building Information Modelling - Adding intelligence to laser and image based surveys of European classical architecture', ISPRS Journal of Photogrammetry \& Remote Sensing, vol. 76, pp. 89 102

Obe, R. and Hsu, L. 2011, PostGIS in action. 2nd edition. Manning Publications Co. ISBN 9781617291395

Ozdemir,E, Remondino, F, 2018, Segmentation of 3D photogrammetric point cloud, 13th 3D GeoInfo Conference, 12 October 2018, Delft.
Over, M., Schilling, A., Neubauer, S. and Zipf, A, 2010. Generating web-based 3D City Models from OpenStreetMap, The current situation in Germany. Comput. Environ. Urban Syst., 34, 496-507.

Parish, Y. and Mueller P., 2001. Procedural Modelling of Cities, ACM Siggraph 2001, vol. 12, no. 17, pp. 301

Petrescu, P., 2007. The use of GIS technology in cultural heritage, Proceedings of the XXI International CIPA Symposium, 01-06 October 2007, Athens, Greece. III. http://www.cultureindevelopment.nl/cultural_heritage/what_is_ cultural_heritage IV.

Pimpler, E., 2015. Programming ArcGIS with Python Cookbook. Packt Publishing Ltd.

Ryoo, H. G., Kim, S., Kim, J. S., and Li, K. J., 2017. Development of an extension of GeoServer for handling 3D spatial data. In Free and Open Source Software for Geospatial (FOSS4G) Conference Proceedings (Vol. 17, No. 1, p. 6)

Stiny, G. and Gips, J., 1971. Shape grammars and the generative specification of painting and sculpture, in Information Processing, C. V. Freiman, ed., Cambridge, MA: North -Holland, 1971, pp. $125-135$.

Yao, Z., Nagel, C., Kunde, F., Hudra, G., Willkomm, P., Donaubauer, A., Adolphi, T. and Kolbe, T.H., 2018. 3DCityDB-a 3D geodatabase solution for the management, analysis, and visualization of semantic 3D city models based on CityGML. Open Geospatial Data, Software and Standards, 3(1), p.5 